\title{
GIS COMBINED WITH MCE TO EVALUATE LAND QUALITY
}

\author{
Fengchang Xue ${ }^{1, *}$, Zhengfu Bian ${ }^{1}$ \\ ${ }^{1}$ School of Environment Science and Spatial Informatics of China University of Mining and \\ Technology \\ * Corresponding author, Address: School of Environment Science and Spatial Informatics of \\ China University of Mining and Technology, Xuzhou, Jiangsu province, China, 221008, Email: \\ xfc9800@126.com, Tel: 0516-83521039
}

Abstract: The evaluation of land quality plays an important role in the study of land resources. Some software of GIS was applied to evaluate land quality in recent years. There is some limitation in Appling GIS to evaluate land quality directly. GIS combined with MCE (Multi-Criteria Evaluation) can eliminate limitation existing in using GIS singly. In this thesis key technology of evaluating land quality with GIS and MCE is studded, including methods of confirming evaluation criteria, plotting spatial cells, diffusing spatial attribute value and combining spatial data in numeric way. Technology above was applied in plotting out requisition blocks of land in Tongshan country. The research indicated that the technology of GIS combined with MCE can integrate multiple source information associating with land quality commendably, and achieve measurable land quality evaluation.

Keywords: GIS, MCE, Land, Evaluation

\section{INTRODUCTION}

The study of land resources in China and abroad since the 1970s has evolved into an important and comprehensive field of applied research in earth sciences (Leng Shuying, 1999). The evaluation of land quality plays an important role in this field. More attention is centralizing land quality indicators and how to measure land quality (Su Biyao, 2001). Some software of GIS was applied to evaluate land quality based on Overlay analysis in recent years.

Xue, F. and Bian, Z., 2008, in IFIP International Federation for Information Processing, Volume 258; Computer and Computing Technologies in Agriculture, Vol. 1; Daoliang Li; (Boston: Springer), pp. 215-222. 
Geographic Information System (GIS) emerged in 1960s, which functions of data managing, map showing and spatial analysis are widely used in land evaluation. Overlay analysis of GIS can mix attribute value distributing in different layers, which leads to a new layer containing some new attribute value. There is some limitation in appling overlay analysis to evaluate land quality directly (Ye Jia-An, 2006): (1) General overlay analysis can not comparatively consider weightiness of layers; (2) There is not effective way to confirm threshold value of consecutively distributing variable.

Multi-Criteria Evaluation (MCE) is one of applications of multiple criteria decision making (MCDM). Generally, it is composed of two forms: multiobject evaluation and multi-attribute evaluation. As an application of multiattribute evaluation, land quality evaluation is the process analyzing land quality differentia based on multiple attributes associated with evaluation region.

GIS combined with MCE can eliminate the limitation existing in using GIS singly and achieve measurable evaluation of land quality.

\section{THE PRINCIPLE OF GIS COMBINED WITH MCE}

GIS combining with MCE is a process combining multiple source information associating with geographical location to expose relations hiding in resource information. Main content of it are as follows:

(i) Confirming the goal of evaluation;

(ii) Choosing criteria: to confirm effectual factors using for evaluating, which founds a standard for judgment;

(iii) Confirming weights of factors: to confirm comparative weightiness of factors;

(iv) Calculating factor's value diffused in every spatial cells: to diffuse attribute value of factors to make them distributing spatially and numerically based on GIS;

(v) Calculating combined value of spatial cells: to achieve combined value of spatial cells through numeric overlay calculation;

(vi) Classing spatial cells according to their combined value to achieve evaluation results. 


\section{KEY TECHNOLOGY OF APPLYING GIS AND MCE TO EVALUATE LAND QUALITY}

\subsection{Founding Criteria and Calculating Weights}

The criteria used in MCE must be fit for analyzing the particularity of the question, requirements of which as follows:

(i) Which can mapping the aim of the evaluation synthetically;

(ii) Which can be expressed measurably;

(iii) Factors in criteria are independent.

Weight of factors is used to judge the weightiness of factors in criteria. Generally, methods used to calculate it as follows:

(i) Subjective method: such as Delphi Method, Pairing Comparison, Priority Order Decision and so on.

(ii) Objective method: such as Principal Component Analysis, Entropy Technology, Multiobjective Programming Model and so on.

All of methods above are based on determinate information, but uncertainties widely exist in objective world, human cognition and data processing (Shi Wen-Zhong, 2006). To fit for practical application, it was request that relations of spatial data must be expressed under the condition of lacking determinate and accurate information. Rough set is a novel mathematical tool for dealing with uncertainties and imprecision of geographic information, which can be used to represent uncertainties in multi-levels spatial knowledge (Deng Min, 2006). The follow is a method based on condition and decision attributes of a given knowledge expression system to acquire criteria using useful data and useful characters existing in observed data.

A given knowledge system can be expressed as $\mathrm{S}=<\mathrm{U}, \mathrm{C}, \mathrm{D}, \mathrm{V}, \mathrm{F}\rangle$, where $\mathrm{U}$ is universe, $A=C \cup D$ is the set of attributes on $U, C$ and $D$ are the sets of condition and decision attributes, $\mathrm{V}$ is the value set of $\mathrm{A}, \mathrm{F}: \mathrm{U} \times \mathrm{A} \rightarrow \mathrm{V}$ is information mapping from $\mathrm{U} \times \mathrm{A}$ to $\mathrm{V}$.

In the attributes set $A=C \cup D, x \in X$ is an attribute. Resolution enhancement of $\mathrm{X}$ after $\mathrm{x}$ is joined into $\mathrm{X}$ can be taken as a weightiness of $\mathrm{X}$ belonging to $\mathrm{X}$. The resolution is more enhanced, $\mathrm{x}$ for $\mathrm{X}$ is more important.

The concept of the attribute weightiness degree (Miao Duo-qian, 2002) in rough sets can be used to evaluate the importance of the factor.

Let $X \subseteq C$ be a attribute set and $\mathrm{x} \in \mathrm{C}$ be a attribute. Marking Sigx as the attribute weightiness degree of $\mathrm{x}$ for $\mathrm{X}$ : 


$$
\operatorname{Sin}(\mathrm{x})=1-\frac{|X \bigcup\{x\}|}{|X|},|X|=|\operatorname{IND}(X)|=\sum_{i=1}^{n}\left|X_{i}\right|^{2}
$$

Where $\operatorname{IND}(X)$ is undistinguished relations on $X$.

The attribute weightiness degree represents the attribute's affecting on decision-making and reflects the different factors' importance in evaluation, so that objective weight of attribute in evaluation can be confirmed.

\subsection{Spatial Cell Plotting}

The object of plotting spatial cells is to form units to process spatial analysis and evaluation based on GIS. To fit for GIS, spatial cells must possess two characters as follows at least (Paul A. Longley, 2004):

(i) The model of plotting spatial cells should be repeated infinitely so that it can be used to map views in any scale.

(ii) The model of plotting spatial cells can be divided into infinitely subtle ones so that spatial elements in any resolution can be created and represented.

Generally, there are two models to plot spatial cells: shapely model and unshapely model. Shapely model refers to plot spatial cells in equal shapes, such as Archimedes spatial plotting. Unshapely model refers to plot spatial cells according to boundaries of some irregularly distributing spatial attributes, such as administration boundaries, Voronoi map and so on.

In examples of this article, to evaluate land quality, the shapely model and the unshapely model were applied synthetically: for attributes only associated with region, such as local economic development, land output and so on, plotted spatial cells according to administration boundary and land block boundary; for attributes that not only associated with distance but also with orientation, such as effect degree of towns, advantage degree of roads and so on, plotted spatial cells according to regular grid. Furthermore, attributes value of all kinds of spatial elements were integrated to a new sets of appropriate grids. In process of plotting spatial cells, units of interiorly equal and exteriorly dissimilar were obtained by controlling grid size. These units composed of basal cells to carry on spatially analyzing to achieve land quality evaluation.

\subsection{Diffusing Spatial Attribute Value}

Factors associated with land quality are being forms of scattering dot, line and field in space, but these factors affect more area around them. In order to represent above affection, spatial interpolation was employed, such as Kriging Interpolation, spline interpolation, polynomial interpolation. In 
example of the article, linearly attenuate function and exponential attenuate function were employed, which as follows:

(i) Linearly attenuate function: $\mathrm{e}_{\mathrm{ij}}=\mathrm{f}_{\mathrm{i}} \times(1-r)$;

(ii) Exponential attenuate function: $\mathrm{e}_{\mathrm{ij}}=\left(\mathrm{f}_{\mathrm{i}}\right)^{1-r}$.

where, $e_{i j}$ is diffused attribute's functional value of factor $i$ in cell $j ; f_{i}$ is attribute's functional value of factor $i$; $r$ is distance from $j$ cell to $i$ factor's center.

\subsection{Numeric Overlay Calculation of Spatial Data}

Overlay analysis is basal function of GIS, including arithmetical overlay, logic Overlay, fuzzy Overlay and so on. There is some limitation in general overlay analysis, such as not comparatively considering weightiness of layers, no way to confirm threshold value of consecutively distributing variable and not be able to evaluate all of spatial elements roundly, for example, not be able to order results of evaluation.

Because of limitations above, general overlay analysis can not meet for the requestment of evaluating land quality based on GIS and MCE.

Numeric overlay calculation of spatial data refers to that taking attribute value of spatial object as consecutive variable, and transforming them into some new value which falling into some special numeric zone, after these, factors' new value is weighting and linearly combined. All of these are based on spatial cell plotting and spatial attribute value diffusing. Spatial cell plotting divides consecutive space into equal spatial cells and spatial attribute value diffusing transforms consecutive attribute value to discrete dot value which belongs to different spatial cells. After depositing data above in date table, numeric overlay calculation can be carried on as follows:

$$
\mathrm{S}=\sum_{i}^{n} D_{i} \times P_{i}
$$

where, $\mathrm{S}$ is value of evaluation, $\mathrm{D}_{i}$ is measurable value of factor, $\mathrm{P}_{i}$ is weight of factor.

\section{EXAMPLE}

We applied technology above to plot out requisition blocks of land in TongShan country. It succeeded to plot land in TongShan country into some blocks in equal condition and achieve grades of land requisition blocks. Table 1 describes factors in criteria and their weights, Figure 1 is demonstration of diffusing spatial attribute value, Figure 2 describes plotting spatial cell in evaluation region, Figure 3 is grades map of land requisition blocks. 
Table 1. Factors in criteria and their weights

\begin{tabular}{llccccc}
\hline $\begin{array}{l}\text { Factors in } \\
\text { criteria }\end{array}$ & $\begin{array}{l}\text { Land } \\
\text { type }\end{array}$ & $\begin{array}{c}\text { Land } \\
\text { output }\end{array}$ & $\begin{array}{c}\text { Land } \\
\text { condition }\end{array}$ & $\begin{array}{c}\text { effect degree } \\
\text { of towns }\end{array}$ & $\begin{array}{c}\text { advantage } \\
\text { degree of roads }\end{array}$ & $\begin{array}{c}\text { Local economic } \\
\text { development }\end{array}$ \\
\hline $\begin{array}{l}\text { Weight of } \\
\text { factors }\end{array}$ & 16.22 & 19.68 & 15.11 & 17.32 & 14.23 & 17.44 \\
\hline
\end{tabular}
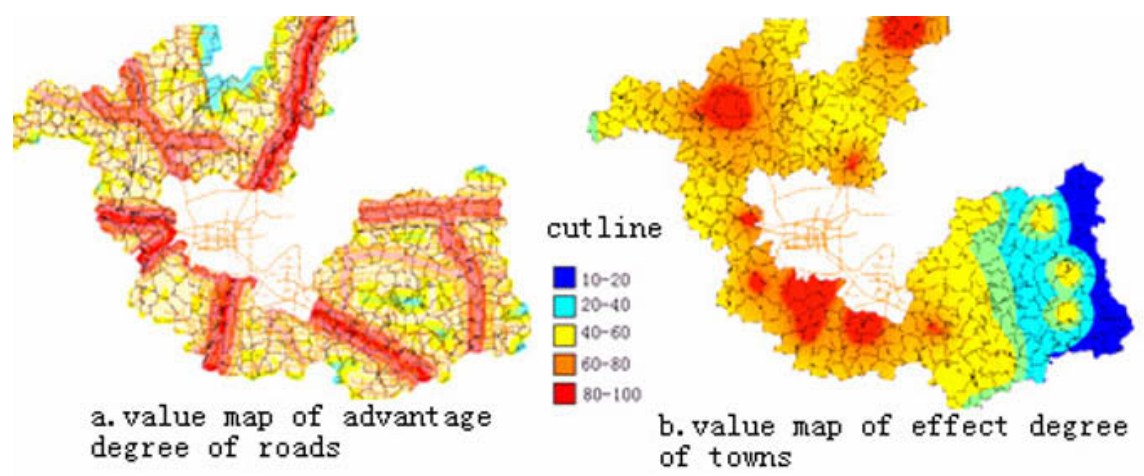

Figure 1. The demonstration of diffusing spatial attribute value

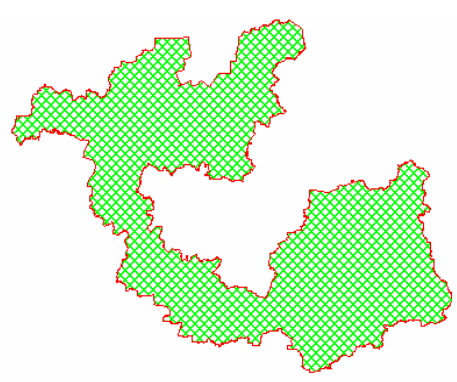

Figure 2. Plotting Spatial cell in evaluation region

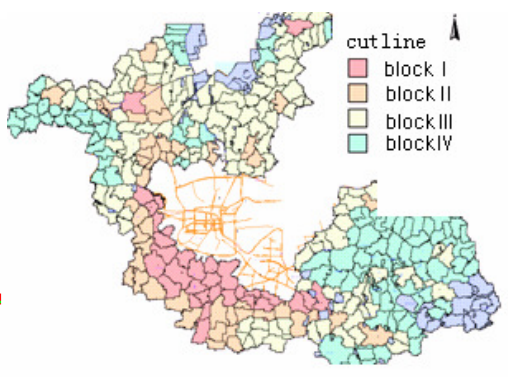

Figure 3. Grades map of land requisition blocks

\section{CONCLUSIONS}

Land quality holds many connotations, such as land environment quality, land economy quality and land management quality, which are involved in extensive spatial data and social statistical data. To combine multiple source information associating with land quality, functions of GIS must be expanded. MCE increased the decision ability of GIS. 
Key technology of evaluating land quality with GIS and MCE was studed and is summed up as follows:

i. confirming evaluation criteria;

ii. plotting spatial cells;

iii. diffusing spatial attribute value;

iv. combining spatial data in numeric way.

Technology above was applied in plotting out requisition blocks of land in Tongshan country. The research indicated that the technology of GIS combined with MCE can integrate multiple source information associating with land quality commendably, and achieve measurable land quality evaluation.

\section{ACKNOWLEDGEMENTS}

Authors are grateful to the Land Management Bureau of Tongshan Country for its financial support for this research.

\section{REFERENCES}

Leng SY, et al. New Progresses of International Study on Land Quality Indicators (Lqis). Acta Geographica Sinica, 1999, 54(2): 177-186.

Su BY, Land Qualities Evaluation of Cangwu. Journal of Nanjing Normal University (Natural Science Edition), 2001, 24(2): 104-110.

Jin XB, et al. Land Quality Evaluation of Land Reclamation Project Based on Farmland Gradation. Journal of Nanjing Forestry Universty (Natural Sciences Edition), 2006, 30: 93-97.

Zhang L, et al. Preliminary Study on Concept and Measurement of Land Quality. Journal of Nanjing University (Natural Sciences), 2004, 40: 378-390.

Tian SM, et al. Land Quality Evaluation Aided By Gis - A Case Study In Quzhou County, Hebei Province. Journal of China Agricultrural Resources and Regional Planning, 2002, 123(13): 16-20.

Shi CY, et al. Evaluation of Land Quality Based on Gis - A Case Study on Paddy Field in Suzhou. Acta Pedologica Sinica, 2001, 38(3): 248-256.

Nie QH, et al. The Quality Evaluation and Site Assessment of Agricultural Land Based on GIS: A Case Study in Liangxiang Town, Fangshan District, Beijing. Scientia Geographica Sinica, 2000, 20(4): 307-314.

Wang XF, et al. Preliminary Study on Landscape-Scale Land Quality Quantitative Assessment in Luan Mining Area. Journal of Soil and Water Conservation, 2007, 21(1): 197-201.

Xu MJ, et al. A Preliminary Study of Land Quality Indicators in Local Scale. System Sciences and Comprehensive Studies in Agriculture. 2006, 122(13): 201-206. 
Wang J, et al. Review on Spatial Variability and Scale Effects of Land Quality. Progress in Geography. 2005, 24(4): 28-36.

Li XY, et al. Land Quality Evaluation of Land Reclamation Project Based on Farmland Gradation. Journal of Nanjing Forestry University. 2006, 20(2): 99-104.

Ouyang JL, et al. Agricultural Land Evaluation Based on Different Crop Planting at County Level and Household Behavior. Resources Science. 2003, 125(15): 58-66.

Ye JA, GIS and Programming Support System. Science Press, 2006.

Paul AL, et al. Geographic Information System. Publishing House of Electronics Industry, 2004, 464-473.

Shi WZ, Indeterminacy Theory of Spatial Data and Spatial Analysis, Science Press, 2006, 7-11.

Deng M, et al. Rough-Set Representation of GIS Data Uncertainties with Multiple Granularities. Acta Geodaetica et Cartographica Sinica, 2006, 35(1): 64-69.

Miao DQ, et al. The Calculation of Knowledge Granulation and its Application. Systems Engineering - Theory \& Practice, 2002, 48-56.

Paul AL, et al. Geographic Information System. Publishing House of Electronics Industry, 2004, 474-495.

Xu JH, Mathematic Methods in modern geography. Higher education Press, 2002, 35.

Zheng HL, Rough Sets Theory and Applications. Chong Qing university publisher, 1996, 44-55. 